Journal of Advanced Research in Fluid Mechanics and Thermal Sciences

Journal homepage: www.akademiabaru.com/arfmts.html ISSN: 2289-7879

\title{
Effect of Temperature on The Performance of Naphtha and Kerosene as Viscosity Reduction Agents for Improving Flow Ability of Basrah-Iraq Heavy Crude Oil
}

\author{
Ali Nasir Khalaf ${ }^{1, *}$, Asaad A. Abdullah², Raheem Khazal Al-Sabur ${ }^{3}$ \\ Department of Chemical Engineering, College of Engineering, University of Basrah, Iraq \\ Department of Materials Engineering, College of Engineering, University of Basrah, Iraq \\ Department of Mechanical Engineering, College of Engineering, University of Basrah, Iraq
}

\begin{tabular}{|c|c|}
\hline ARTICLE INFO & ABSTRACT \\
\hline $\begin{array}{l}\text { Article history: } \\
\text { Received } 11 \text { January } 2021 \\
\text { Received in revised form } 19 \text { March } 2021 \\
\text { Accepted } 26 \text { March } 2021 \\
\text { Available online } 2 \text { July } 2021 \\
\text { Keywords: } \\
\text { Temperature; drag reduction agent } \\
\text { (DRA); crude oil; naphtha; kerosene }\end{array}$ & $\begin{array}{l}\text { Naphtha and kerosene are mixed with Iraqi heavy crude oil at different concentrations } \\
\text { rounded between ( } 3-12 \text { ) wt.\%, in order to reduce viscosity to enhance its followability. } \\
\text { This research investigated drag reduction (\%Dr) in heavy oil mixtures at different flow } \\
\text { rates ( } 2 \text { to } 10 \mathrm{~m}^{3} / \mathrm{hr} \text { ) in temperature range } 20-50^{\circ} \mathrm{C} \text {. The experimental results proved } \\
\text { that Naphtha offered } 40 \% \text { reduction in pressure drop. The Power law model was } \\
\text { adopted in this study to empirically correlate fiction factor (f) and the percentage of } \\
\text { drag reduction (\%Dr) from experimental data for Reynolds number range (534-14695) } \\
\text { and the concentration range from } 3 \text { to } 12 \mathrm{wt} \% \text {. }\end{array}$ \\
\hline
\end{tabular}

\section{Introduction}

The pipeline flow rate can significantly increase or the pumping energy costs can be decreased when using Drag Reducing Agent (DRA). DRAs are materials reduce the turbulence when they are added to a turbulent flow stream, they can reduce friction at the pipeline walls or improve the flow regime and thus the pressure drop decreased significantly also the pumping costs [1,2]. Transporting crude oil through a network of pipelines is considered one of the main challenges for exporting oil countries. Drag reducing additives offer the best quick, temporary solution to such a problem. Decreasing the frictional pressure drop across the pipeline is the net result of using a DRA in turbulent flow. When a polymer DRA was added below 200 ppm, the frictional pressure drop and turbulence have been shown to be reduced up to $80 \%[3,4]$.

The use of polymers is often restricted to structure changes during application which leads to irreversible degradation. Wyatt et al., [5] use xanthan gum as drag reducer at different concentrations from $20 \mathrm{ppm}$ to $200 \mathrm{ppm}$, and observed, in comparison to drag reduced synthetics, that xanthan gum is less suitable for shear reduction. In the temperature range from $50^{\circ} \mathrm{C}$ to $60^{\circ} \mathrm{C}$, Xanthan gum shows higher reduction in viscosity. This happens as xanthan molecules start to change

\footnotetext{
${ }^{*}$ Corresponding author.

E-mail address: alinasserey@yahoo.com
}

https://doi.org/10.37934/arfmts.84.1.135147 
the configuration from helixes to coils type, which leads to better drag reduction [6]. Le Brun et al., [7] investigated three types of poly(acrylamide-co-naamps) and pure phpaam as polymers induced a mechanical polymer degradation and a drag reducer in 1" horizontal bore circular cross-section pipe. It is found that the existence of naamps groups can enhance the ability to reduce the frictional drag while the sensitivity to mechanical degradation remains unchanged. Rashid et al., [8] studied the drag reduction effect of PAA (Poly acrylic acid) at different concentrations (0, 50, 100, 150, 200 and 250 $\mathrm{ppm}$ ) and $0.0081 \mathrm{~m}^{3} / \mathrm{s}$ flow rate of Iraqi crude oil in 0.0508 pipe diameter. They conclude that the DRA addition saves the pumping power and increases the produced flow by $28.48 \%$ and $4.05 \%$, respectively.

Polymer degradation is the major limitation in applying and testing polymers as a drag reducing agent. It has been well proven that the dragging efficiency of polymer is affected and greatly dependent on two types of mechanical and chemical degradation [9]. In recent studies, surfactants (Surface-Active Agents) are chemical compounds known as surfactants, which are, constituted of hydrocarbon portion (tail) and polar (or ionic) portion (head), may be used as a substitute for polymers in DRA applications [10]. A solution of high enough concentration to form aggregates called micelles. Micelles may automatically stick to an interface to minimize interface tension and improve mixing between phases. The micelles play a vital role in the mechanisms of turbulence, suppression, which can reduce the friction even lower than some high polymer solutions [11].

Abdul-Hadi and Khadom [12] studied oil flow in pipeline of $0.0508 \mathrm{~m} \mathrm{ID}$ with four different kinds of SLES, SLS, SDBS, and SS surfactants. They found that at $250 \mathrm{ppm}$ of SDBS, 55\% drag reduction was found. Gudala et al., [13] studied the reduction of viscosity, energy consumption, and pressure drop in crude oil flow using potato starch. The results showed a significant reduction in viscosity, by addition potato starch to heavy crude oil, also reduction in pressure drop, head loss, and energy requirements. They concluded that after adding potato starch to $85 \%$ heavy crude $+15 \%$ water, the maximum reduction in viscosity was $80 \%$ at $40^{\circ} \mathrm{C}$. Al-Adwani and Al-Mulla [14] conducted experimental work concerning the use of three different types of surfactants (cationic, anionic, and zwitterionic) with 1:1:1 molar ratio to reduce the viscosity of 14.85 API and 16.33 API Kuwaiti crude oil samples. By using nonisothermal rheometric measurements for 40, 50 and 70 ppm aqueous solutions. They observed that maximum reduction in viscosity occurs at $70 \mathrm{ppm}$ cationic solution for 14.85 API and 70 ppm zwitterionic solution for $16.33 \mathrm{API}$.

One of the efficient methods of heavy crude oil transportation of is to dilute crude oil with less viscous solvents, such as naphtha, kerosene and lighter crudes. This approach avoids the pressure drop and reduces pumping costs $[15,16]$. In recent years, the blending of crude oil with polar groups appears to be of some value of minimizing heavy oil viscosity at a constant rate of dilution for acceptable limits for pumping and transportation [17]. Dilution with naphtha has led to a decrease in the viscosity of crude oil from $250 \mathrm{cP}$ to $40 \mathrm{cP}$. Hart [18] suggested to reduce the viscosity of heavy oil for pipeline transport requirements by adding naphtha and organic solvent. Kerosene-diluted crude oil is an expensive technique that requires a large amount of diluent to minimize the heavy oil viscosity to a transportation limit [19]. Faris et al., [20] studied experimentally drag reduction caused by toluene and naphtha solutions for different concentration and flow rates, in laminar and turbulent pipe flow. Pipes 0.058 and $0.025 \mathrm{~m}$ I.D. were used. They found that the maximum drag reduction was $40.48 \%$ and $34.32 \%$, at $27^{\circ} \mathrm{C}$ for naphtha and toluene receptively. They presented an equation that correlates pipe dimeter, flow rate, friction loses, and solvent concentration by using dimensional analysis.

Kumar et al., [21] studied the influence of temperature on crude oil viscosity when heating crude oil with addition of $2000 \mathrm{ppm}$ from $25^{\circ} \mathrm{C}$ to $40^{\circ} \mathrm{C}$ of surfactant. Their results show that adding 2000 ppm of surfactant is more effective in reducing viscosity than heating crude oil to $40^{\circ} \mathrm{C}$ without any 
additives. The reduction was greater than heating pure crude oil without any additives for laminar and turbulent flow regions Based on the Shu [22] correlation, Arinina et al., [23] carried out a series of experiments in order to develop a generalized master curve to determine the effect of combined temperature-concentration relationship that provide the required and suitable viscosity level for successful pipe transportation of heavy oil. Three types of diluents were used in their study (light gas oil, spindle oil, and light oil) at viscosity limit of 0.2-0.4 Pa.s.

In the current work, the effect of temperature in the range from $25^{\circ} \mathrm{C}$ to $50^{\circ} \mathrm{C}$ when using Naphtha and Kerosene at concentrations of $3,6,9,12,15 \mathrm{wt}$.\% as drag reducing agents for the flow of BasrahIraq crude oil were studied. In addition, the effect of additive concentration on mixture viscosity, drag reduction percentage, and friction factor were studied. Furthermore, the experimental data points are also used to develops a new empirical correlation for friction factor and drag reduction which account the effect of Reynold number and concentration for crude oil mixture flow rate range from 2 to $10 \mathrm{~m}^{3} / \mathrm{hr}$.

\section{Experimental Part}

\subsection{Materials}

Iraqi crude oil named Basrah heavy oil supplied from Basrah refinery, were used in the experimental work. Naphtha and kerosene also supplied from the same refinery. The specifications of these liquids are listed in Table 1.

Table 1

The Physical Properties of Heavy Crude Oil, Naphtha, and Kerosene

\begin{tabular}{llll}
\hline Physical Property & Heavy Crude Oil & Naphtha & Kerosene \\
\hline API Gravity $15.6^{\circ} \mathrm{C}$ & 24.0 & 87.7 & 46.0 \\
Specific gravity at $15.6^{\circ} \mathrm{C}$ & 0.910 & 0.646 & 0.797 \\
Viscosity at $20^{\circ} \mathrm{C} / \mathrm{cSt}$ & 57.3 & 0.5 & 1.70 \\
Naphthenes, vol \% & 17.3 & 5.7 & 24.5 \\
Paraffins, vol \% & 33.7 & 94.3 & 57.4 \\
Carbon, wt. \% & 84.2 & 83.6 & 85.5 \\
\hline
\end{tabular}

\subsection{Density and Viscosity Measurements}

Crude oil and solvent viscosity and density of were measured at different concentrations and temperatures ranging from $\left(20^{\circ} \mathrm{C}\right.$ to $\left.50^{\circ} \mathrm{C}\right)$. According to the standard method (IP 190) (API 1988), the density determination was carried out using pyknometer size $50 \mathrm{~cm}^{3}$. The pyknometer calibration was done by determining the density of the distillate water. The weights of the samples are determined by a sensitive type digital balance. In order to achieve the test temperature, the sample was placed in a water bath form which could maintain a temperature of $\pm 0.1^{\circ} \mathrm{C}$ of the measured temperature. Ensure all traces of moisture are eliminated by drying with a current hot air that passes through the capillary pyknometer. Both density and viscosity measurements are conducted at atmospheric pressure. Viscosity calculations were performed at different temperatures using different sizes of viscometer BS / U tube which satisfy the standard method (IP.71) for measuring the kinematic viscosity range $\left(0.9-10000 \mathrm{~mm}^{2} / \mathrm{s}\right)$.

The viscometer was placed in a water bath that could hold the temperature within $\pm 0.1^{\circ} \mathrm{C}$ of the temperature chosen. The standard test method and the international standard ISO 3105, with accuracy $\pm 0.006 \mathrm{cP}$, determined the measurement of kinematic viscosity. The viscometers were calibrated using pure known viscosity hydrocarbon. For measuring the time, a stop watch was used. 


\subsection{Experimental Flow Loop}

Figure 1 shows a schematic diagram of the experimental flow system. The experimental flow comprised of $50.8 \mathrm{~mm}$ diameter and $1440 \mathrm{rpm}$ displacement gear pump and solution container with a size about one $\mathrm{m}^{3}$ was installed. The flow measurements are performed with a carbon steel pipe of $0,03175 \mathrm{~m}$ in diameter. Test section was $2 \mathrm{~m}$ long and is located away from the entrance section. The equivalent length was about $(1.6 \mathrm{~m})$, the minimum entrance length.

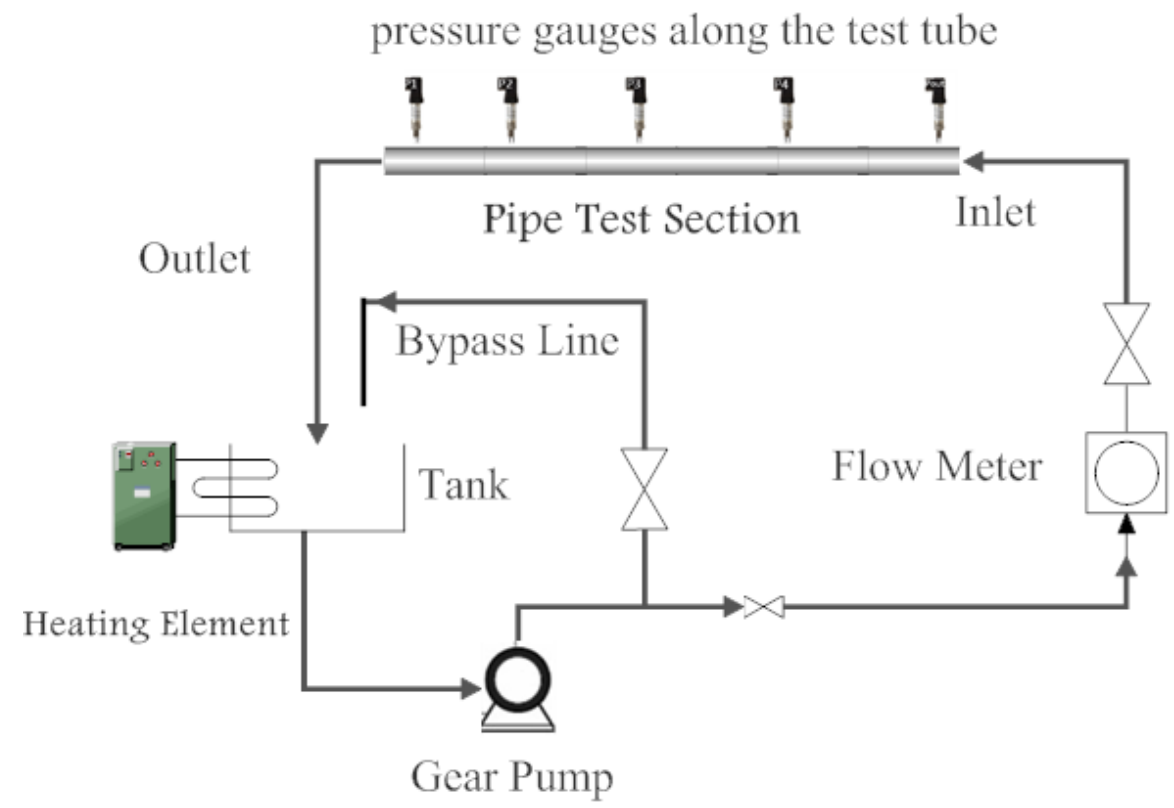

Fig. 1. Schematic of experimental setup.

The fluid flow was controlled with ball valve and pressure drop was measured by a mercury Utube manometer. Crude oil flow of was measured by a float flow meter, $50.8 \mathrm{~mm}$ in diameter and a flow rate of 10 to 100 litres per minute. The pressure drop was calculated when the crude oil with solvent was forced into the circulation flow system to measure the dragging effect of additives under turbulent flow conditions. Initially, the container was filled with 130 litres of fluid crude oil. Through rotating a gear pump, the fluid may flow through the pipe.

The same procedure has been used to measure the pressure drop for each flow rate and additives concentration. To ensure homogenous mixture, drag-reduction additives were diluted before they were added to the feed tank. The exact amount of concentrated additive solution was diluted by around half a litre of test fluid, stirred by a shaker for about 1 hour, and left at a lab temperature for 24 hours. The prepared solution was added carefully into the feed tank. Typically, about 20 minutes of mixing by operating the pump were allowed prior to performing the test. The Naphtha and Kerosene percentage varied from 3 and $15 \mathrm{wt} . \%$ while the change in temperature was from $20^{\circ} \mathrm{C}$ and $50^{\circ} \mathrm{C}$ and flow rates ranged from 2 and $10 \mathrm{~m}^{3} / \mathrm{hr}$. In order to measure drop in pressure at different flow rates and temperatures, the system was sent to the test section through the crude oil pump. $A$ heating coil placed inside the crude oil tank to assure that the temperature is constant the temperature is also determined by a thermometer at the entrance to the piping system. 


\section{Results and Discussions}

Adding small quantities of DRA to the turbulent flow system leads to a decree in the pressure drop required to obtain the same flow rate, or increases the flow at a constant value of the pressure drop. In this study the Reynolds number (Re), viscosity reduction parentage, drag percentage reduction $(\% \mathrm{Dr})$, percentage flow increase $(\% \mathrm{FI})$, and friction factor $(\mathrm{f})$ were calculated using the following equations $[24,25]$.

$$
\begin{aligned}
& R_{e}=\frac{\rho v d}{\mu} \\
& \% D_{r}=\frac{\Delta P_{b}-\Delta P_{a}}{\Delta P_{b}} \\
& \% F I=\left(\frac{1}{1-\left(\frac{\% D_{r}}{100}\right)^{0.55}}-1\right) \times 100 \\
& f=\frac{d \Delta P}{2 L \rho v^{2}} \\
& \% \mu_{r}=\left(\frac{\mu_{r e f}-\mu}{\mu_{r e f}}\right) \times 100
\end{aligned}
$$

where $\rho$ is the mixture density, $v$ is the velocity, $d$ is the pipe diameter, $\mu \mu$ is the viscosity of the mixture in Cst., $\mu_{\text {ref }}$ is the reference viscosity in Cst at a specific temperature (viscosity of the crude oil at $\left.20^{\circ} \mathrm{C}\right), \Delta P_{b}$ and $\Delta P_{a}$ are the pressure drop before and after addition of naphtha or kerosene, and $L$ is the pipe length.

\subsection{Degree of Viscosity Reduction}

Measurements of viscosity were carried out at different naphtha and kerosene concentrations and temperatures $\left(20^{\circ} \mathrm{C}\right.$ to $\left.50^{\circ} \mathrm{C}\right)$. Temperature has a major effect on heavy crude viscosity, naphtha, and on crude oil with naphtha for concentration from 3 wt.\% to $15 \mathrm{wt} . \%$, as shown in Figure 2. The rising viscosity with increasing temperature, low viscosity and pressure decrease would increase mechanical and fluid transport efficiency through improved flow capacity. Kinematic viscosity was measured at different concentrations varied from 3 to $15 \mathrm{wt} . \%$ and temperatures $\left(20^{\circ} \mathrm{C}\right.$ to $\left.50^{\circ} \mathrm{C}\right)$. As Figure 3 shows the degree of viscosity reduction has increased with an increase in naphtha and kerosene temperature and concentration.

From experimental results it was observed that $70 \%$ reduction in viscosity occurred when the temperature is $50^{\circ} \mathrm{C}$ for pure crude oil. For crude oil and naphtha mixtures, $76 \%$ reduction in viscosity was observed at $50^{\circ} \mathrm{C}$ for $3 \mathrm{wt} . \%$ and $73 \%$ reduction for $3 \mathrm{wt} . \%$ kerosene at the same temperature. Increasing the concentration to $9 \% \mathrm{wt}$ for both naphtha and kerosene, the reduction in viscosity was increased explicitly. It is observed that the maximum reduction in viscosity was $84 \%$ for naphtha and $80 \%$ for kerosene. This indicates that the addition of naphtha and kerosene to crude oil is alternative method for viscosity reduction. 


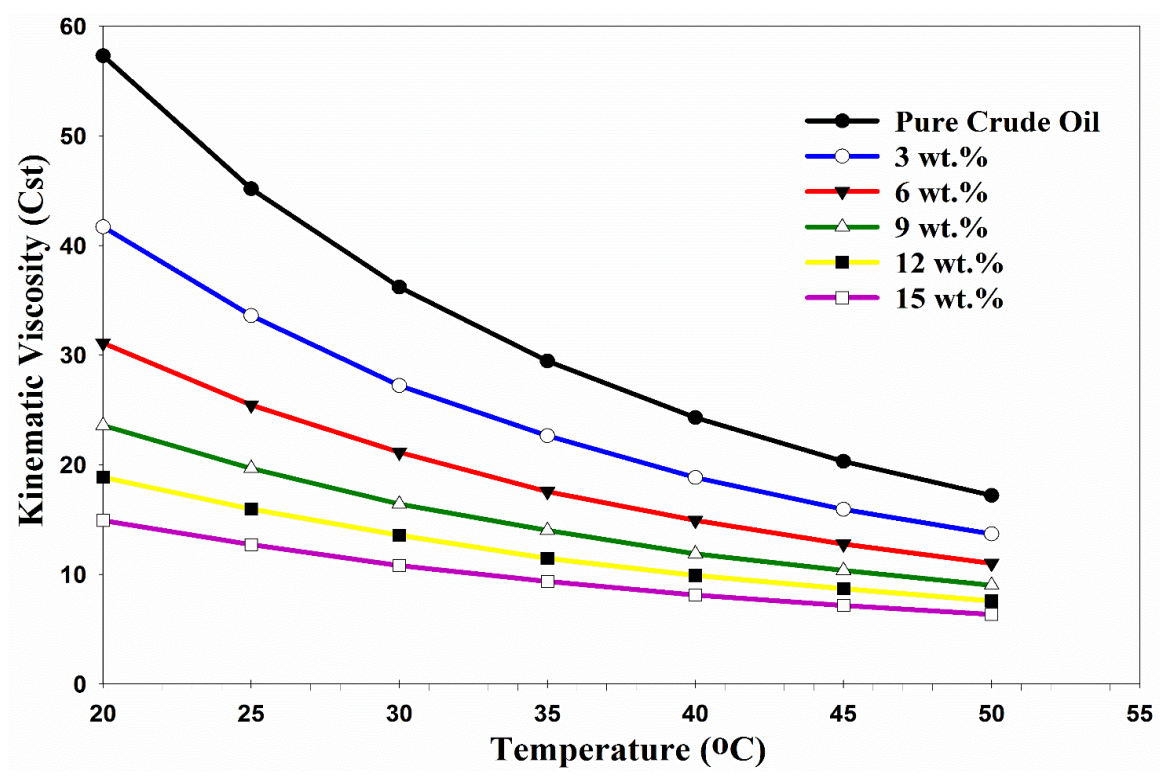

Fig. 2. Effect of temperature on viscosity of heavy crude oil for different concentration of Naphtha

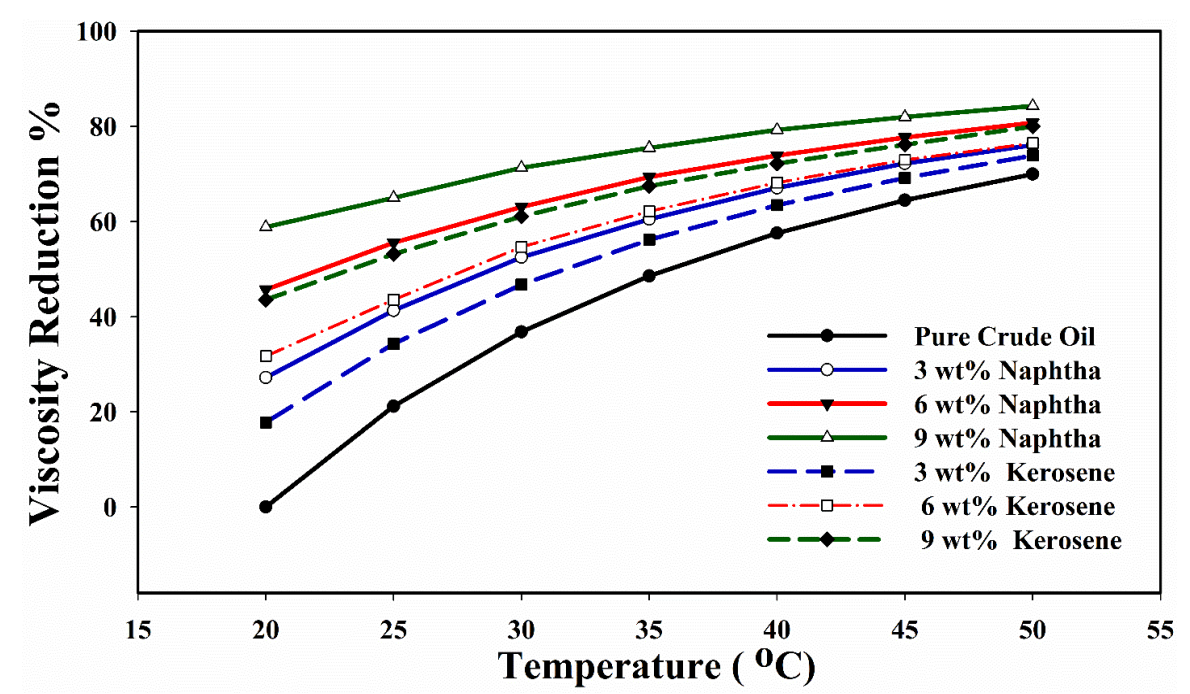

Fig. 3. Effect of temperature on degree of viscosity reduction at different concentrations for naphtha and kerosene

\subsection{Drag Reduction Analysis}

Drag reduction is described as the difference in pressure drop due to the friction losses along a pipeline, compared with untreated fluid and fluid containing drag reducer at a constant flow rate. With drag reducer present, the pressure drops in the pipeline found mainly depend on solvent concentration, flow rate and temperature. Figure 4 shows a comparison between naphtha and kerosene at $25^{\circ} \mathrm{C}$ and $50^{\circ} \mathrm{C}$ for different concentrations 3-15 wt.\%. The results showed, that within the range of additive concentration, a gradual increase of percentage drag reduction was observed by increasing the concentration within certain Reynolds number $\left(10 \mathrm{~m}^{3} / \mathrm{hr}\right)$.

For constant naphtha flow rate $\left(10 \mathrm{~m}^{3} / \mathrm{hr}\right)$ with different concentration, Figure 5 indicated that percentage drag reduction was noticeably affected by increasing temperature. Thus, at $50^{\circ} \mathrm{C}$ about $40 \%$ drag reduction was achieved by using $15 \mathrm{wt} . \%$, while the values for lower concentration $3 \mathrm{wt} . \%$ 
were about $33.8 \%$ at the same operating conditions. The results illustrated in Figure 3 and Figure 4, fit well with the results obtained by other researchers with the use of naphtha as a drag reducer [20].

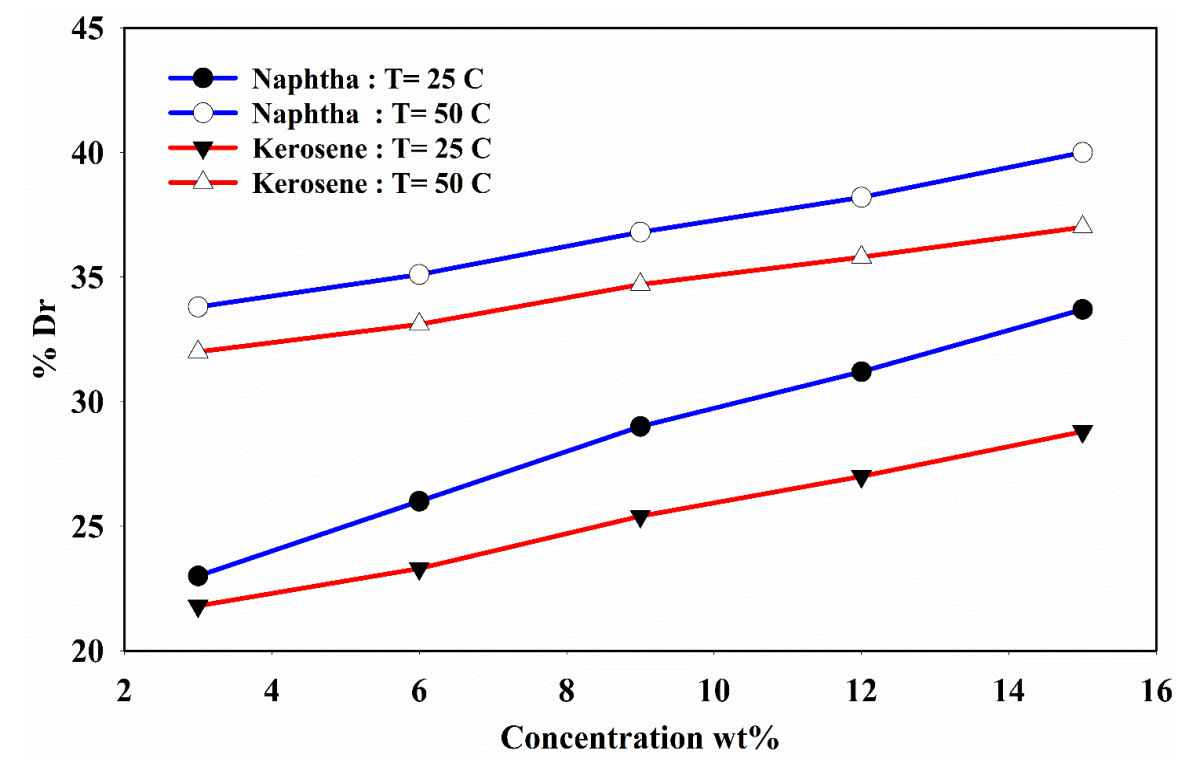

Fig. 4. Effect of concentration on percent drag reduction for naphtha and kerosene, at $25^{\circ} \mathrm{C}$ and $50^{\circ} \mathrm{C}$

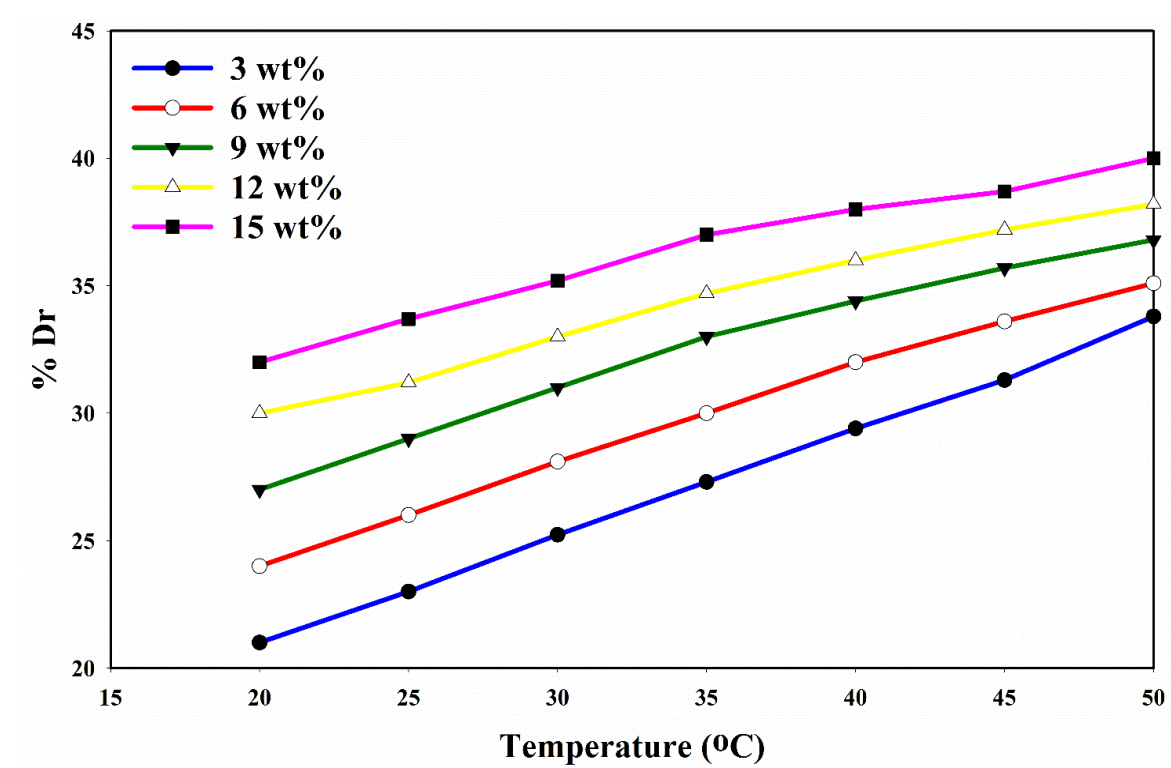

Fig. 5. Effect of temperature and different concentration on percent drag reduction for naphtha crude oil mixture

\subsection{Effect of Flow Rate}

One of the interesting factors in the study of drag reduction is the effect of flow rate on percent drag reduction and its relation to the turbulence and the effectiveness of the drag reducer additives. Different flow rates from 2 to $10 \mathrm{~m}^{3} / \mathrm{hr}$ were chosen to study this effect for naphtha and kerosene at different concentrations as represented in Figure 6 and Figure 7.

These figures shows that the percent drag reduction is increased as flow rates increase. Increasing the flow rate means increasing the velocity which was represented by the Reynolds number (Re). In general, turbulent flow experiences random changes of linear quantities such as velocity, pressure, 
temperature and density around their mean value. However, the velocity quantity is the most important parameter for turbulent flow that means increasing the degree of turbulence inside the pipe; this will make the DRA to be more effective. Figure 8 represents the effect of flow rate for 9 wt.\% naphtha at $25^{\circ} \mathrm{C}$ and $50^{\circ} \mathrm{C}$, increasing temperature and flow rates for constant concentration leads to a decrease in viscosity, thus the drag reduction enhanced to reach higher values. The friction factor for naphtha at constant temperature $25^{\circ} \mathrm{C}$, for various concentrations and $\mathrm{Dr} \%$, percentage flow increase $\mathrm{Fl} \%$ are shown in Table 2.

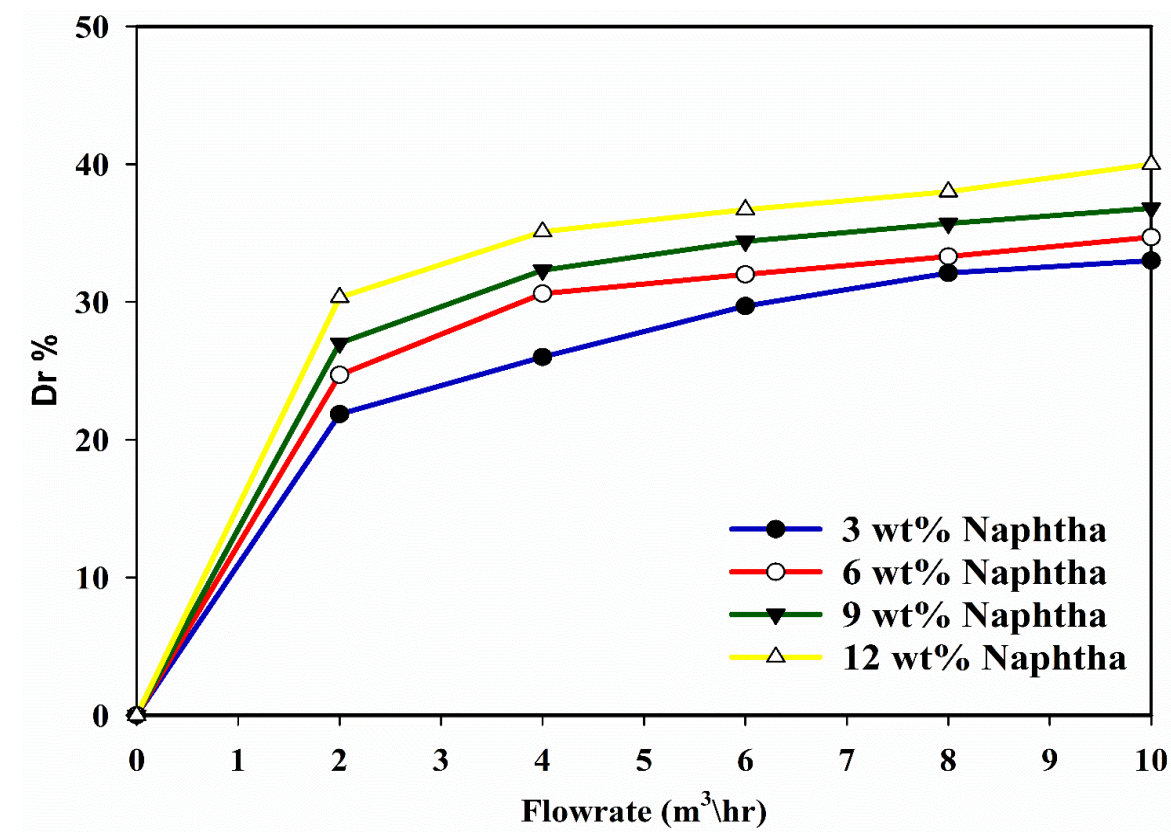

Fig. 6. Effect of flow rate on drag reduction for different concentration of naphtha crude oil mixture at $25^{\circ} \mathrm{C}$

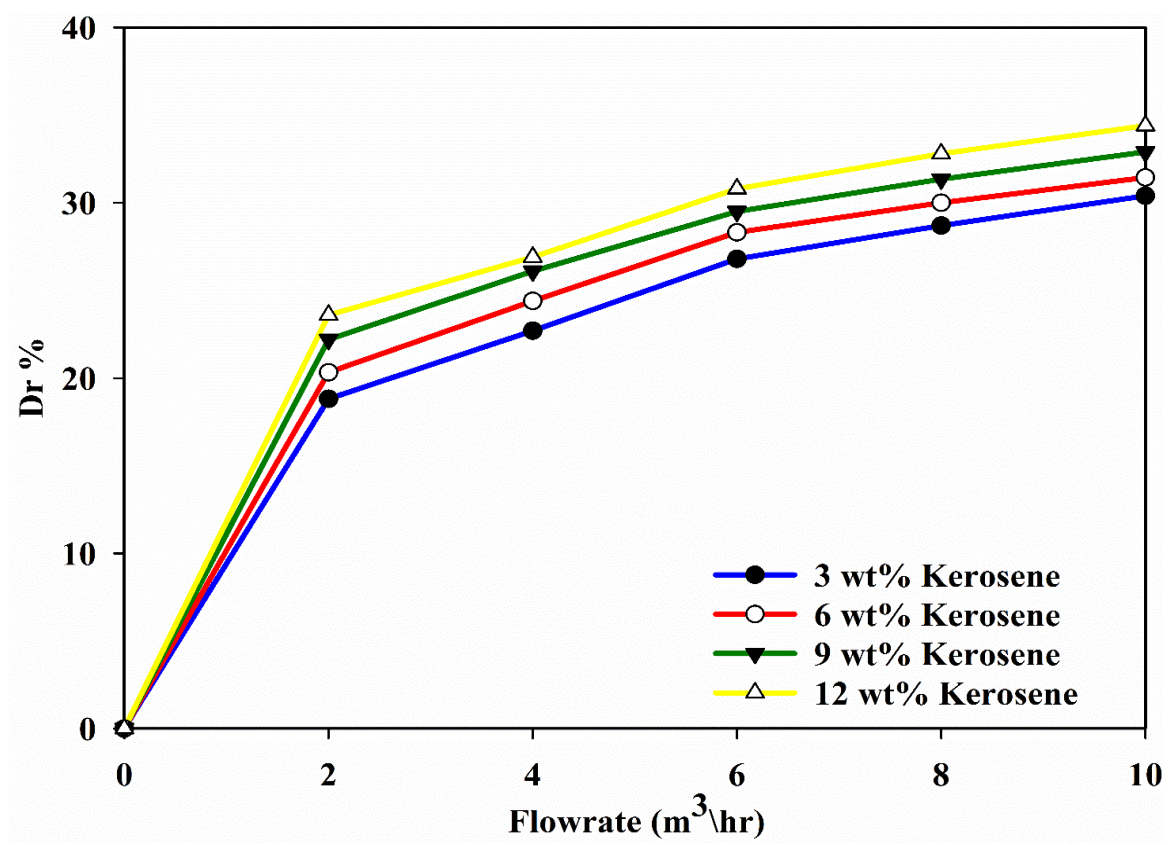

Fig. 7. Effect of flow rate on drag reduction for different concentration of kerosene crude oil mixture at $25^{\circ} \mathrm{C}$ 


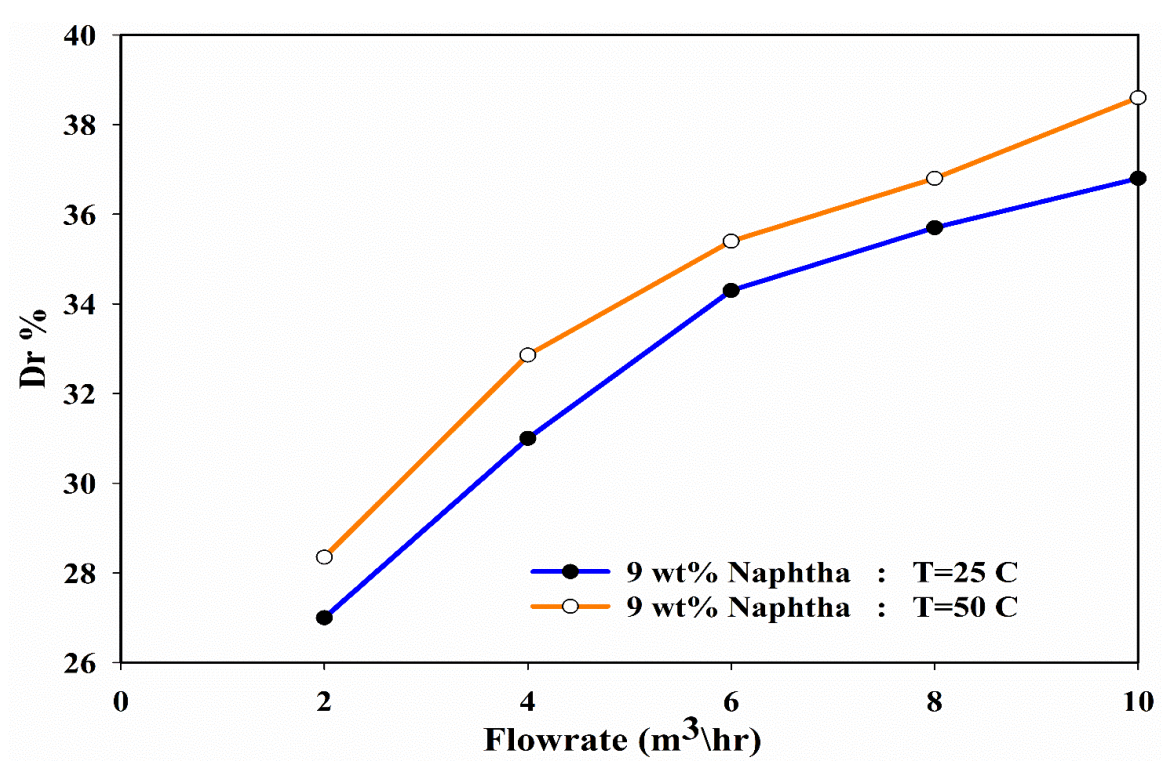

Fig. 8. Effect of flowrate and temperature on percent drag reduction for 9 wt.\% naphtha crude oil mixture

Figure 9 shows variation of drag reduction percentage for $3 \mathrm{wt} . \%$ and $12 \mathrm{wt} . \%$ of naphtha and kerosene. It is shown that Dr\% increases with increasing the concentration and flow rate. This is because that the addition of DRA reduces the viscosity and therefore the Reynolds number will increase which leads to decrease the friction factor, thereby the pressure drops decreases. Therefore, the highest percentage drag reduction of about $40 \%$ was achieved by using naphtha at $12 \mathrm{wt} . \%$ and $10 \mathrm{~m}^{3} / \mathrm{hr}$ flow rate, which are the conditions within the considered range, as shown also in Table 2 . Viscosity and density of crude oil mixtures was evaluated, to check whether the additives affect the API gravity of used crude oil. The result shows that API gravity for 3,6, and 12 wt.\% naphtha was $27.13,29.11$, and 31.15 respectively.

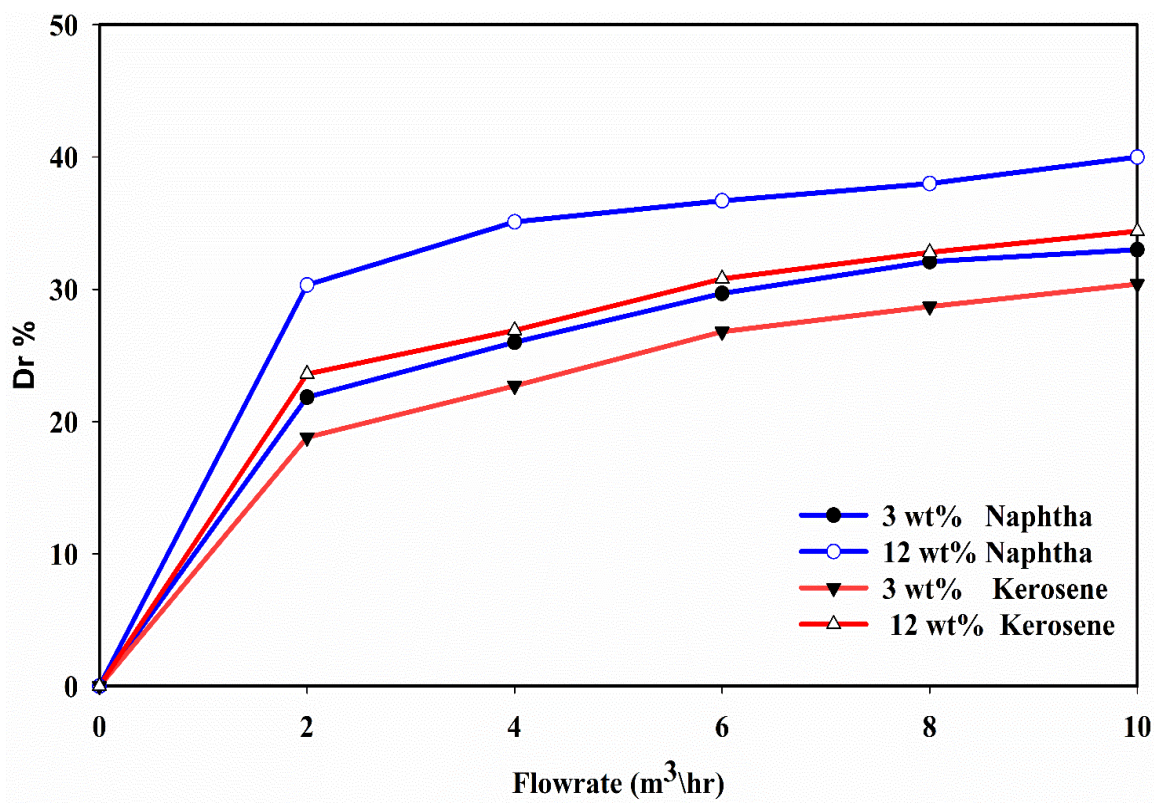

Fig. 9. Comparison between naphtha and kerosene reduction for $3 \mathrm{wt. \%}$ and $12 \mathrm{wt} . \%$ at different flow rate 
Table 2

Experimental data for different concentration of naphtha at $25^{\circ} \mathrm{C}$

\begin{tabular}{lllllll}
\hline $\begin{array}{l}\text { Flow rate } \\
\left(\mathrm{m}^{3} / \mathrm{hr}\right)\end{array}$ & $\mathrm{Re}$ & $\begin{array}{l}\text { Concentration } \\
\text { wt.\% }\end{array}$ & DR\% & $\mathrm{Fl} \%$ & $\mathrm{f}$ & $\mathrm{f}_{\text {crude oil }}$ \\
\hline 2 & 530 & 3 & 21.0 & 12.16 & $5.98 \times 10^{-3}$ & $7.13 \times 10^{-3}$ \\
& 700 & 6 & 24.7 & 14.44 & $5.48 \times 10^{-3}$ & \\
& 1100 & 12 & 30.3 & 18.00 & $5.16 \times 10^{-3}$ & \\
4 & 1600 & 3 & 26.0 & 15.26 & $4.53 \times 10^{-3}$ & $6.01 \times 10^{-3}$ \\
& 2100 & 6 & 30.6 & 18.20 & $4.49 \times 10^{-3}$ & \\
& 3300 & 12 & 35.1 & 21.16 & $4.27 \times 10^{-3}$ & \\
6 & 3500 & 3 & 29.7 & 17.62 & $4.11 \times 10^{-3}$ & $5.43 \times 10^{-3}$ \\
& 4500 & 6 & 32.0 & 19.11 & $3.97 \times 10^{-3}$ & \\
& 6800 & 12 & 36.7 & 22.23 & $3.70 \times 10^{-3}$ & \\
& 5600 & 3 & 32.1 & 19.17 & $3.68 \times 10^{-3}$ & $5.05 \times 10^{-3}$ \\
& 7000 & 6 & 33.3 & 19.96 & $3.63 \times 10^{-3}$ & \\
10 & 12900 & 12 & 38.8 & 23.66 & $3.40 \times 10^{-3}$ & \\
& 8200 & 3 & 33.0 & 19.77 & $3.48 \times 10^{-3}$ & $4.78 \times 10^{-3}$ \\
& 10100 & 6 & 34.7 & 20.89 & $3.40 \times 10^{-3}$ & \\
\hline
\end{tabular}

\subsection{Flow Regimes Analysis}

In order to analyze the performance of drag reducing by naphtha and kerosene, the most common method of presenting the experimental and study the effects of flow rate and physical properties is the relation between friction factor $(f)$ and Reynolds number (Re). Figure 10 shows that the friction factor decreases by increasing the additive concentration, and Reynolds number as listed in Table 2. It can be noticed that the friction factor for the concentration range $3 \mathrm{wt} . \%-12 \mathrm{wt}$.\% have less friction factor compared to that for pure crude oil flow. It is obvious that most of the experimental data points are below the Poisuelle's law equation for laminar flow.

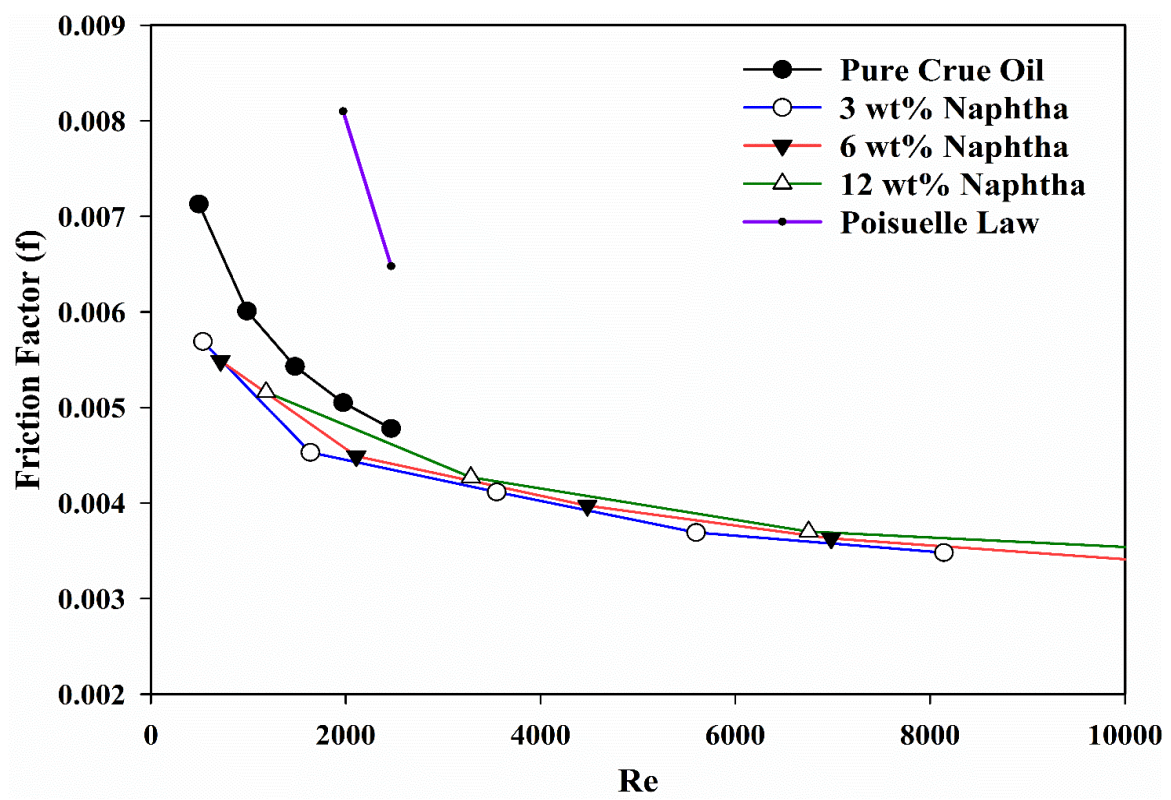

Fig. 10. Friction factor versus Reynolds number at different concentration of naphtha at $25^{\circ} \mathrm{C}$ 
Laminar flow region $(\mathrm{Re}<2300)$, where the friction factor follows Poisuelle's law as follows

$f=\frac{16}{R_{e}}$

Turbulent flow (Re > 3000), where the friction factor follows Blasius law:

$f=0 \cdot 0791 R^{-0.25}$

One of the most important aspects in drag reduction experiment data, is the maximum drag reduction asymptote. Since there are no empirical equations to predict the conditions of a maximum drag reduction for naphtha and kerosene, we use Virk asymptote region, which was suggested to define the maximum possible limit of drag reduction. This asymptote was originally based on the experiment data for polymeric solutions. The friction factors for $\mathrm{Re}>\mathbf{4 0 0 0}$ given by Virk formula:

$f=0 \cdot 58 R_{e^{-0.58}}$

Figure 11 shows the behaviour of selected samples from the experimental results for friction factor and (Re) varied from 4000 to 16000 . At higher flow rate, most of the experimental data points are located between Blasius law and Virk asymptote and close to the Virk asymptote line. To reach such asymptote, higher additive concentration and flow rates are needed. Higher concentrations must be considered to reach the maximum drag point. However, increasing concentrations leads to increasing the cost of drag reduction agent raw materials. Therefore, it was difficult to reach Virk asymptote without affecting the crude oil properties.

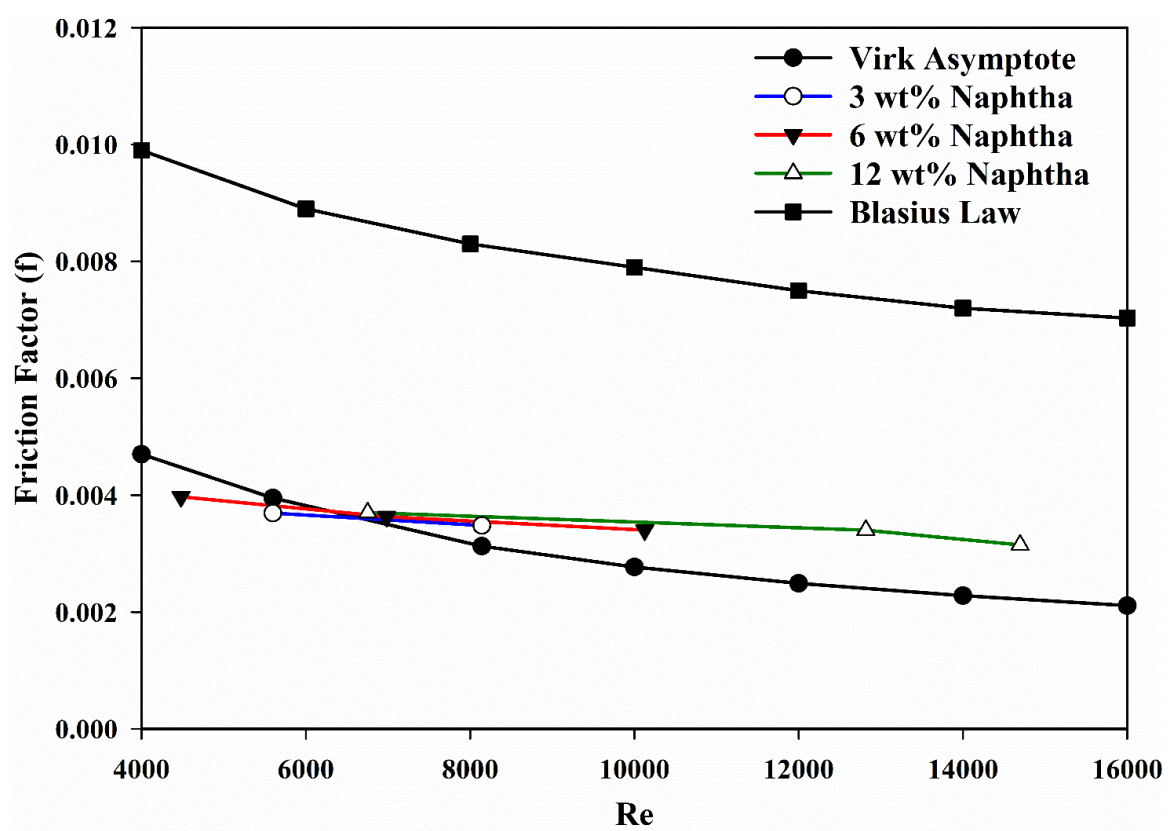

Fig. 11. Friction factor versus Reynolds number at different concentration of naphtha at $25^{\circ} \mathrm{C}$ in turbulent flow region $\mathrm{Re}>3000$

For the purpose of making practical results more suitable for application to different ranges of concentration and flow rate for naphtha and kerosene, the experimental data may be written in the form of power law equation type as a function of Reynold number and concentration. By applying the method of nonlinear least square, the coefficients of the correlation for Reynolds number range 
(530 to 14700) and the concentration range from 3 to $12 \mathrm{wt} . \%$. The coefficients for this system were summarized in the following with 0.9977 and 0.976 correlation coefficient for fiction factor and drag reduction.

$f=0 \cdot 01717 R_{e}^{-0 \cdot 1816} C^{0.0307}$

$D_{r} \%=9 \cdot 452 R_{e}^{0 \cdot 1231} C^{0 \cdot 107}$

where $\mathrm{C}$ is the concentration of naphtha in wt.\%.

\section{Conclusions}

The viscosity reduction efficiency of various mixtures of naphtha and kerosene was examined in crude oil flow loop. Viscosity reducing agents is strongly dependent on its concentration and Reynolds Number. Percentage of drag reduction increases with increasing concentration at given velocities. This provides a significant indication for commercial applications in large-scale pipeline for the same crude oil -solvent system. Values of calculated friction factor for naphtha - oil mixture positioned toward Virk line for maximum drag-reduction, especially for high concentrations. At higher temperature $76 \%$ reduction in viscosity was observed at $3 \mathrm{wt} . \%$ for naphtha-crude oil mixture. A correlation between drag reduction percentage and Reynolds Number was established. Naphtha was significantly reducing the friction factor and finally the pressure drop which has led to significant cost savings for crude oil transportation.

\section{References}

[1] Al-Wahaibi, T., A. Abubakar, A. R. Al-Hashmi, Y. Al-Wahaibi, and A. Al-Ajmi. "Energy analysis of oil-water flow with drag-reducing polymer in different pipe inclinations and diameters." Journal of Petroleum Science and Engineering 149: 315-321. https://doi.org/10.1016/i.petrol.2016.10.060

[2] Ghannam, Mamdouh T., and Nabil Esmail. "Flow enhancement of medium-viscosity crude oil." Petroleum Science and Technology 24, no. 8 (2006): 985-999. https://doi.org/10.1081/LFT-200048166

[3] Hassanean, M. H., M. E. Awad, H. Marwan, A. A. Bhran, and M. Kaoud. "Studying the rheological properties and the influence of drag reduction on a waxy crude oil in pipeline flow." Egyptian Journal of Petroleum 25, no. 1 (2016): 39-44. https://doi.org/10.1016/i.ejpe.2015.02.013

[4] Albusairi, Bader H., and Adam Al-Mulla. "A study of flow properties of Kuwaiti crude oil obtained from different sources." Journal of Petroleum Science and Technology 7, no. 1 (2017): 79-90.

[5] Wyatt, Nicholas B., Casey M. Gunther, and Matthew W. Liberatore. "Drag reduction effectiveness of dilute and entangled xanthan in turbulent pipe flow." Journal of Non-Newtonian Fluid Mechanics 166, no. 1-2 (2011): 25-31. https://doi.org/10.1016/i.jnnfm.2010.10.002

[6] Sohn, J-I., C. A. Kim, H. J. Choi, and M. S. Jhon. "Drag-reduction effectiveness of xanthan gum in a rotating disk apparatus." Carbohydrate Polymers 45, no. 1 (2001): 61-68. https://doi.org/10.1016/S0144-8617(00)00232-0

[7] Le Brun, Niccolò, Ivan Zadrazil, Lewis Norman, Alexander Bismarck, and Christos N. Markides. "On the drag reduction effect and shear stability of improved acrylamide copolymers for enhanced hydraulic fracturing." Chemical Engineering Science 146 (2016): 135-143. https://doi.org/10.1016/j.ces.2016.02.009

[8] Rashid, Farhan Lafta, Haider Nadhom Azziz, and Shaheed Mahdi Talib. "Experimental investigation of drag reduction by a polymeric additive in crude oil flow in horizontal pipe." Journal of Advanced Research in Fluid Mechanics and Thermal Sciences 60, no. 1 (2019): 15-23.

[9] Den Toonder, J. M. J., A. A. Draad, G. D. C. Kuiken, and F. T. M. Nieuwstadt. "Degradation effects of dilute polymer solutions on turbulent drag reduction in pipe flows." Applied Scientific Research 55, no. 1 (1995): 63-82. https://doi.org/10.1007/BF00854224

[10] Ashrafizadeh, S. N., E. Motaee, and V. Hoshyargar. "Emulsification of heavy crude oil in water by natural surfactants." Journal of Petroleum Science and Engineering 86 (2012): $137-143$. https://doi.org/10.1016/i.petrol.2012.03.026

[11] Hadri, Ferhat, and Sylvain Guillou. "Drag reduction by surfactant in closed turbulent flow." International Journal of Engineering Science and Technology 2, no. 12 (2010): 6876-6879. 
[12] Abdul-Hadi, Ali A., and Anees A. Khadom. "Studying the effect of some surfactants on drag reduction of crude oil flow." Chinese Journal of Engineering 2013 (2013): 1-6. https://doi.org/10.1155/2013/321908

[13] Gudala, Manojkumar, Shirsendu Banerjee, Rama Mohan Rao T, Tarun Kumar Naiya, and Ajay Mandal. "The effect of a bio additive on the viscosity and the energy requirement on heavy crude oil flow." Petroleum Science and Technology 36, no. 2 (2018): 99-107. https://doi.org/10.1080/10916466.2017.1405030

[14] Al-Adwani, Hamad, and Adam Al-Mulla. "The analysis of drag reduction in Kuwaiti crude oil samples using surfactants and polyacrylamide." Journal of Petroleum Exploration and Production Technology 9, no. 3 (2019): 22352245. https://doi.org/10.1007/s13202-018-0590-9

[15] Aburto, Jorge, Elizabeth Mar-Juarez, and Clemente Juarez-Soto. "Transportation of heavy and extra-heavy crude oil by pipeline: A patent review for technological options." Recent Patents on Chemical Engineering 2, no. 2 (2009): 86-97. https://doi.org/10.2174/2211334710902020086

[16] Saniere, A., I. Hénaut, and J. F. Argillier. "Pipeline transportation of heavy oils, a strategic, economic and technological challenge." Oil \& Gas Science and Technology 59, no. 5 (2004): $455-466$. https://doi.org/10.2516/ogst:2004031

[17] Gateau, P., I. Hénaut, L. Barré, and J. F. Argillier. "Heavy oil dilution." Oil \& Gas Science and Technology 59, no. 5 (2004): 503-509. https://doi.org/10.2516/ogst:2004035

[18] Hart, Abarasi. "A review of technologies for transporting heavy crude oil and bitumen via pipelines." Journal of Petroleum Exploration and Production Technology 4, no. 3 (2014): 327-336. https://doi.org/10.1007/s13202-0130086-6

[19] Santos, R. G., W. Loh, A. C. Bannwart, and O. V. Trevisan. "An overview of heavy oil properties and its recovery and transportation methods." Brazilian Journal of Chemical Engineering 31, no. 3 (2014): 571-590. https://doi.org/10.1590/0104-6632.20140313s00001853

[20] Faris, H. A., N. A. Sami, A. A. Abdulrazak, and J. S. Sangwai. "The performance of toluene and naphtha as viscosity and drag reducing solvents for the pipeline transportation of heavy crude oil." Petroleum Science and Technology 33, no. 8 (2015): 952-960. https://doi.org/10.1080/10916466.2015.1030079

[21] Kumar, Ravindra, Gauri Sankar Bora, Shirsendu Banerjee, Ajay Mandal, and Tarun Kumar Naiya. "Application of naturally extracted surfactant from Madhuca long folia to improve the flow properties of heavy crude oil through horizontal pipeline." Journal of Petroleum Science and Engineering 168 (2018): 178-189. https://doi.org/10.1016/i.petrol.2017.12.096

[22] Shu, W. R. "A viscosity correlation for mixtures of heavy oil, bitumen, and petroleum fractions." Society of Petroleum Engineers Journal 24, no. 03 (1984): 277-282. https://doi.org/10.2118/11280-PA

[23] Arinina, Marianna, Kirill Zuev, Valery Kulichikhin, and Alexander Malkin. "Superposition of temperature and diluent concentration for the viscosity reduction of heavy crude oil." Journal of Dispersion Science and Technology 42, no. 2 (2021): 270-277. https://doi.org/10.1080/01932691.2019.1679167

[24] Li, Pei-Wen, Yasuo Kawaguchi, and Akira Yabe. "Feasibility study of new heat transportation system with dragreducing surfactant additives." In Proc Symposium on Energy Engineering in the 21st Century, Hong Kong, China, vol.1, pp. 716-722. 2000. https://doi.org/10.1299/ismefed.2000.172

[25] Hasan, Shadi W., Mamdouh T. Ghannam, and Nabil Ismael. "Heavy crude oil viscosity reduction and rheology for pipeline transportation." Fuel 89, no. 5 (2010): 1095-1100. https://doi.org/10.1016/j.fuel.2009.12.021 